\title{
Antihypertensive Effect of Captopril and Enalapril in Endothelin-Infused Rats
}

\author{
Minoru Yasujima, Keishi Abe, ${ }^{*}$ Masayuki Kanazawa, $\dagger$ \\ Kazunori Yoshida, $\dagger$ Masahiro Kohzuki, $\dagger$ Kazuhisa \\ Takeuchi, $\dagger$ Kazuo Tsunoda, $\dagger$ KeI Kudo, ${ }^{*}$ Masao \\ Hiwatari, Tokutaro Sato and Kaoru Yoshinaga $\dagger$ \\ Institute of Rehabilitation Medicine, Tohoku University \\ School of Medicine 989-68, *Department of Clinical \\ Biology and Hormonal Regulation, and the Second \\ Department of Internal Medicine, Tohoku University School \\ of Medicine, Sendai 980
}

Yasujima, M., Abe, K., Kanazawa, M., Yoshida, K., Kohzuki, M., Takeuchi, K., Tsunoda, K., Kudo, K., Hiwatari, M., Sato, T. and Yoshinaga, K. Antihypertensive Effect of Captopril and Enalapril in Endothelin-Infused Rats. Tohoku J. Exp. Med., 1991, 163 (3), 219-227 — Comparative effects of angiotensin converting enzyme inhibitors and calcium channel blockers were assessed in rats infused chronically with synthetic endothelin. When $50 \mathrm{mg} / \mathrm{kg} /$ day of captopril orally or $6 \mathrm{mg} / \mathrm{kg} /$ day of enalapril intraperitoneally was administered simultaneously with $60 \mu \mathrm{g} / \mathrm{kg} /$ day of endothelin, the systolic blood pressure was on Day $1142.7 \pm 5.9 \mathrm{mmHg}(p<0.05)$ or $128.7 \pm 6.7 \mathrm{mmHg}(p<0.05)$, respectively, compared to the rise to $163.8 \pm 4.7 \mathrm{mmHg}$ when endothelin alone was infused. The antihypertensive effect of captopril or enalapril was sustained for the entire experimental period and was not associated with a significant change in urinary sodium excretion, whereas both drugs induced a significant increase in urine volume. Chronic infusion of angiotensin II intraperitoneally at a subpressor dose $(400 \mu \mathrm{g} / \mathrm{kg} /$ day) reversed the antihypertensive effect of captopril in endothelin-infused rats. When $6 \mathrm{mg} / \mathrm{kg} /$ day of benidipine or $10 \mathrm{mg} / \mathrm{kg} / \mathrm{day}$ of nilvadipine orally was administered simultaneously with $60 \mu \mathrm{g} / \mathrm{kg} /$ day of endothelin, the systolic blood pressure was on Day $1137.0 \pm 2.4 \mathrm{mmHg}(p<0.05)$ or $119.7 \pm 5.9 \mathrm{mmHg}(p<0.05)$, respectively, compared to the rise when endothelin alone was infused. The antihypertensive effect of benidipine or nilvadipine was sustained for the entire experimental period and was not associated with any significant changes in urine volume and urinary sodium excretion. These results indicate that the reduced sensitivity of the peripheral arteries to endothelin may be involved in the mechanism of the hypotensive action of angiotensin converting enzyme inhibitors, dependent on the suppressed angiotensin II formation.

endothelin; ACE inhibitors; calcium channel blockers; blood pressure regulation; conscious rats

Received December 21, 1990 ; revision accepted for publication February 20, 1991.

Address for reprints: Minoru Yasujima, M.D., Institute of Rehabilitation Medicine, Tohoku University School of Medicine, Narugo 989-68, Japan. 
An endothelium-derived 21-residue peptide vasoconstrictor, endothelin, has been isolated from the culture supernatant of porcine aortic endothelial cells (Yanagisawa et al. 1988). The vasopressor response, induced by synthetic endothelin was dependent on extracellular calcium ion and was inhibited by voltagedependent calcium channel blockers (Hirata et al. 1988; Yanagisawa et al. 1988), whereas other possible mechanism has been postulated to be involved in the vasopressor response induced by endothelin (Hirata 1990). We have previously reported that benidipine (Kubo et al. 1985 ; Fujii et al. 1988) and nilvadipine (Ohtsuka et al. 1983), newly developed blockers of calcium channel, reversed the elevation of blood pressure induced by chronic infusion of endothelin in conscious rats (Yasujima et al. 1990a). However, it remains to be elucidated whether the antihypertensive effect of calcium channel blockers in endothelin-infused rats is specific to blockade of calcium channels. Angiotensin converting enzyme inhibitors are potent and well tolerated antihypertensive agents. The mechanism of action of angiotensin converting enzyme inhibitors in lowering blood pressure has not been fully elucidated, although the inhibition of angiotensin II formation (MacGregor et al. 1981; Morton et al. 1982) and of bradykinin degradation (Johnston et al. 1981) may be mainly responsible for the hypotensive action of these drugs.

Therefore, we assessed the comparative effects of angiotensin converting enzyme inhibitors and calcium channel blockers on blood pressure and sodiumwater excretion in rats infused chronically with synthetic endothelin.

\section{Materials and Methods}

Male Sprague-Dawley rats weighing from $150-250 \mathrm{~g}$ were used. All rats were maintained in a humidity- and temperature-controlled room, each rat being housed in a metabolic cage during the study. The rats were fed a regular diet (Oriental CMF, $0.24 \%$ of sodium $/ \mathrm{g}, 0.69 \%$ of potassium/g; Oriental Yeast Co., Tokyo) and free access to tap water. Studies were performed after a 7-day period of acclimatization to the housing, feeding and drinking conditions. The rat were infused with $60 \mu \mathrm{g} / \mathrm{kg} /$ day of a synthetic endothelin, delivered via osmotic minipumps (Alzet ${ }^{\circledR}$; Alzet, Palo Alto, CA, USA) into the jugular vein for up to the 6 days. The vascular catheter (PE 60) was tunneled subcutaneously, and the osmotic minipump was implanted in the interscapular region of the rat's back under pentobarbitone sodium anesthesia (Abbott Laboratories Pty., Ltd., Tokyo). A synthetic endothelin of 21 amino acids purchased from Peptide Institute, Inc. (Osaka) was used in the present experiments and was dissolved in $0.9 \%$ physiological saline. Assuming that endothelin did not degrade during the study, and that the pumps dispensed fluid at the specified rate of approximately $1 \mu \mathrm{l} / \mathrm{hr}$, the infusion dose at a rate of $60 \mu \mathrm{g} / \mathrm{kg} /$ day was chosen to be sufficient to induce a significant elevation of circulating levels of this peptide (unpublished data). The stability of endothelin in the osmotic minipump was examined by comparing the blood pressure response remaining in the solution recovered from the minipump after 6 days of use in the rat to the activities in freshly dissolved endothelin. No difference was observed in the activities between the fresh preparation and the solution recovered from the minipump.

The effect of combined administration of angiotensin converting enzyme inhibitors or calcium channel blockers, with endothelin was assessed in rats on a regular diet. Following 
a 7 day control period, the rats were administered with captopril dissolved into drinking water at a rate of $50 \mathrm{mg} / \mathrm{kg} /$ day, enalapril intraperitoneally via osmotic minipumps at a rate of $6 \mathrm{mg} / \mathrm{kg} /$ day, or benidipine at a rate of $6 \mathrm{mg} / \mathrm{kg} / \mathrm{day}$ or nilvadipine at a rate of $10 \mathrm{mg} /$ $\mathrm{kg}$ /day dissolved in polyethylene glycol by oral gavage once a day, in combination with endothelin intravenously via osmotic minipumps at a rate of $60 \mu \mathrm{g} / \mathrm{kg} /$ day for up to 6 days. In preliminary experiments, the vasopressor response to exogenous angiotensin I as a bolus was examined in anesthetized rats administered with captopril orally at a rate of $50 \mathrm{mg} / \mathrm{kg} /$ day or with enalapril intraperitoneally at a rate of $6 \mathrm{mg} / \mathrm{kg} /$ day for up to 6 days. The vasopressor response to $200 \mathrm{ng} / \mathrm{kg}$ of exogenous angiotensin I was inhibited by $92 \%$ or $95 \%$, respectively, confirming the inhibition of conversion of angiotensin I to angiotensin II by more than $90 \%$. In captopril study, chronic infusion of angiotensin II at a subpressor dose $(400 \mu \mathrm{g} / \mathrm{kg} /$ day $)$ in combination with captopril was assessed in endothelin-infused rats. $\left[\mathrm{Ile}^{8}\right]$ angiotensin II was dissolved in $0.01 \mathrm{~N}$ acetic acid, and delivered intraperitoneally and simultaneously with endothelin and captopril by another osmotic minipump placed in the abdominal cavity. In our previous study to determine the maximum subpressor dose, we assessed continuous angiotensin II infusion at doses of 10, 75, 100, 150 and $200 \mathrm{ng} / \mathrm{min}$ for up to 6 days in conscious rats (Yasujima et al. 1986a). Systolic blood pressure increased dose-dependently at angiotensin II level of 100,150 and $200 \mathrm{ng} / \mathrm{min}$, whereas the changes induced by 10 and $75 \mathrm{ng} / \mathrm{min}$ did not differ from those induced by vehicle infusion. Based on the assumption that the pumps dispenced fluid at a rate of approximately $1 \mu \mathrm{l} / \mathrm{hr}$, the infusion dose at a rate of $400 \mu \mathrm{g} / \mathrm{kg} /$ day should have been sufficient to induce a significant elevation of circulating levels of angiotensin II but not to affect blood pressure (Yasujima et al. 1986b).

Systolic blood pressure in the rats was recorded daily by an indirect tail cuff method (UEDA UR 1000 ; UEDA Industries Co., Tokyo) without anesthesia (Pfeffer et al. 1971). Direct blood pressure measurements were assessed on the final day of experiments in the selected rats $(n=4)$ of each group. With the rats under ether anesthesia, the left femoral artery was cannulated using polyethylene tubing. The catheter was tunneled subcutaneously and exteriorized at the nape of the neck. They were filled with heparinized (10 $\mathrm{U} / \mathrm{ml}$ ) saline solution and sealed by heating. Blood pressure measurements were performed using fully conscious rats. Rats were placed in rectangular boxes with no restriction of movement. The catheter was connected to a pressure tansducer and amplifier (RMP 6004 ; Nihon Kohden, Tokyo) for blood pressure measurements. We confirmed that there was a significant correlation $(\mathrm{r}=0.92, p<0.05)$ between data obtained by both methods. The daily fluid intake, urine volume and urinary sodium excretion were also determined. Urinary sodium was measured with a flame photometer. Statistical analysis of the data between groups was performed by two-way analysis of variance for repeated measurements. Statistically significant difference on each day were isolated by the unpaired $t$ test (between groups). Values are given in terms of mean \pm s.E.

\section{RESULTS}

Basal preinfusion data for each group of rats are summarized in Table 1. Body weight, systolic blood pressure, urine volume and urinary sodium excretion were not significantly different among the 6 groups prior to the infusion. Endothelin alone induced a small but significant elevation of systolic blood pressure. When $50 \mathrm{mg} / \mathrm{kg} /$ day of captopril orally or $6 \mathrm{mg} / \mathrm{kg} /$ day of enalapril intraperitoneally was administered simultaneously with $60 \mu \mathrm{g} / \mathrm{kg} /$ day of endothelin, the systolic blood pressure was on Day $1142.7 \pm 5.9 \mathrm{mmHg}(p<0.05)$ or $128.7 \pm 6.7$ $\mathrm{mmHg}(p<0.05)$, respectively, compared to the rise to $163.8 \pm 4.7 \mathrm{mmHg}$ when endothelin alone was infused (Figs. 1 and 2). The antihypertensive effect of 
TABLE 1. Controls for each group of rats

\begin{tabular}{lcccrc}
\hline \multicolumn{1}{c}{ Rat group } & $n$ & \multicolumn{1}{c}{$\begin{array}{c}\mathrm{BW} \\
(\mathrm{g})\end{array}$} & $\begin{array}{c}\mathrm{SBP} \\
(\mathrm{mmHg})\end{array}$ & $\begin{array}{c}\mathrm{UV} \\
(\mathrm{ml} / \text { day })\end{array}$ & $\begin{array}{c}\mathrm{UNaV} \\
(\mathrm{mEq} / \text { day })\end{array}$ \\
\hline Vehicle & 6 & $185.8 \pm 2.0$ & $135.5 \pm 7.9$ & $9.8 \pm 1.5$ & $0.68 \pm 0.08$ \\
ET & 8 & $190.6 \pm 7.2$ & $143.7 \pm 2.0$ & $7.0 \pm 0.7$ & $0.64 \pm 0.05$ \\
ET + captopril & 6 & $185.0 \pm 3.5$ & $146.7 \pm 4.4$ & $8.2 \pm 0.8$ & $0.59 \pm 0.05$ \\
ET + enalapril & 6 & $206.5 \pm 11.7$ & $142.7 \pm 2.9$ & $10.0 \pm 0.6$ & $0.69 \pm 0.11$ \\
ET + benidipine & 6 & $190.7 \pm 4.2$ & $137.0 \pm 2.4$ & $7.3 \pm 0.9$ & $0.68 \pm 0.07$ \\
ET + nilvadipine & 6 & $204.3 \pm 11.9$ & $140.0 \pm 2.1$ & $7.7 \pm 1.1$ & $0.62 \pm 0.06$ \\
\hline
\end{tabular}

Results are expressed as means \pm s.e. $B W$, body weight; SBP, systolic blood pressure; UV, urine volume; UNaV, urinary sodium excretion; ET, endothelin.

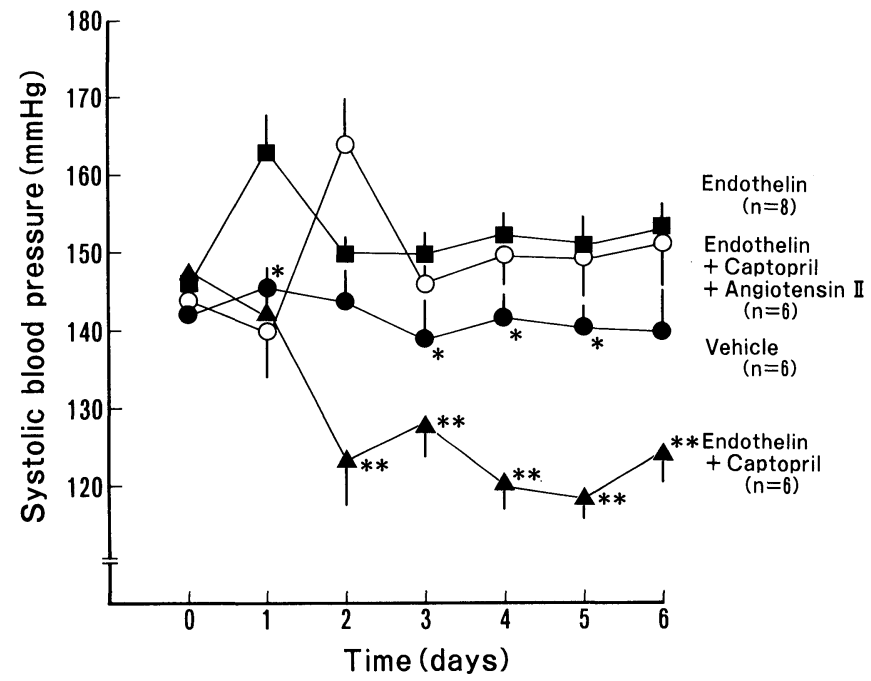

Fig. 1. Effect of captopril on the elevation of blood pressure induced by chronic infusion of endothelin in conscious rats. Daily systolic blood pressure in rats infused with endothelin alone at a rate of $60 \mu \mathrm{g} / \mathrm{kg} /$ day ( $\square$ ), with endothelin combined with $50 \mathrm{mg} / \mathrm{kg} /$ day of captopril ( $\Delta$ ), with endothelin combined with captopril + angiotensin II ( $400 \mu \mathrm{g} / \mathrm{kg} /$ day) (O), and with vehicle alone $(\bullet)$. Results are mean \pm S.E.. Analysis of variance for repeated measurements revealed a significant change in systolic blood pressure in rats given endothelin and captopril $(p<0.01)$, or vehicle alone $(p<0.05)$ compared to that in rats given endothelin alone. ${ }^{*} p<0.05 ;{ }^{* *} p<0.01$ vs. values in rats given endothelin alone. 


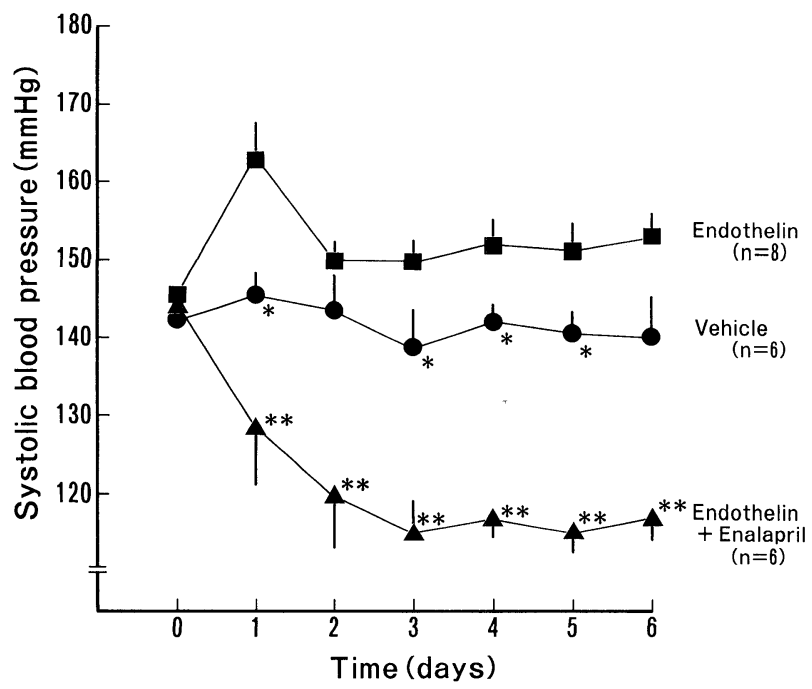

Fig. 2. Effect of enalapril on the elevation of blood pressure induced by chronic infusion of endothelin in conscious rats. Daily systolic blood pressure in rats infused with endothelin alone at a rate of $60 \mu \mathrm{g} / \mathrm{kg} /$ day ( $\square$ ), with endothelin combined with $6 \mathrm{mg} / \mathrm{kg} /$ day of enalapril $(\Delta)$, and with vehicle alone $(\bullet)$. Results are means \pm s.e. Analysis of variance for repeated measurements revealed a significant change in systolic blood pressure in rats given endothelin and enalapril $(p<0.01)$, or vehicle alone $(p<0.05)$ compared to that in rats given endothelin alone. ${ }^{*} p<0.05 ;{ }^{* *} p<0.01$ vs. values in rats given endothelin alone.

captopril or enalapril was sustained for the entire experimental period and was not associated with any significant change in urinary sodium excretion, whereas both drugs induced a significant increase in urine volume (Table 2). In addition, chronic infusion of angiotensin II intraperitoneally at a rate of $400 \mu \mathrm{g} / \mathrm{kg} /$ day reversed the antihypertensive effect of captopril in endothelin-infused rats (Fig. 1)

When $6 \mathrm{mg} / \mathrm{kg} /$ day of benidipine or $10 \mathrm{mg} / \mathrm{kg} /$ day of nilvadipine orally was administered simultaneously with $60 \mu \mathrm{g} / \mathrm{kg} /$ day of endothelin, the systolic blood pressure was on Day $1137.0 \pm 2.4 \mathrm{mmHg}(p<0.05)$ or $119.7 \pm 5.9 \mathrm{mmHg}(p<0.05)$, respectively, compared to the rise when endothelin alone was infused (Fig. 3). The antihypertensive effect of benidipine or nilvadipine was sustained for the entire experimental period and was not associated with any significant changes in urine volume and urinary sodium excretion (Table 2).

\section{Discussion}

In the present study, we clearly demonstrated that both captopril and enalapril, inhibitors of angiotensin converting enzyme, reversed the elevation of blood pressure induced by chronic infusion of endothelin. This attenuation in the blood pressure elevation induced by chronic endothelin infusion was not 
TABLE 2. Effects of ACE inhibitors and calcium channel blockers on urine volume and urinary sodium excretion in endothelin-infused rats

\begin{tabular}{lcrccr}
\hline & $n$ & \multicolumn{1}{c}{ Day 0 } & Day 2 & Day 4 & Day 6 \\
\hline UV (ml/day) & & & & & \\
Vehicle & 6 & $9.8 \pm 1.5$ & $8.8 \pm 1.5$ & $8.4 \pm 1.0$ & $8.3 \pm 1.3$ \\
ET & 8 & $7.0 \pm 0.7$ & $8.6 \pm 1.4$ & $7.6 \pm 0.8$ & $9.6 \pm 0.9$ \\
ET + captopril & 6 & $8.2 \pm 0.8$ & $9.8 \pm 2.1$ & $14.3 \pm 1.9^{* *}$ & $14.3 \pm 3.2$ \\
ET + enalapril & 6 & $10.0 \pm 0.6$ & $12.7 \pm 3.2$ & $17.5 \pm 3.0^{* *}$ & $19.3 \pm 5.1$ \\
ET+ benidipine & 6 & $7.3 \pm 0.9$ & $11.2 \pm 1.9$ & $12.0 \pm 1.5$ & $10.0 \pm 0.4$ \\
ET + nilvadipine & 6 & $7.7 \pm 1.1$ & $11.8 \pm 1.1$ & $11.5 \pm 2.6$ & $9.3 \pm 1.8$ \\
UNaV (mEq/day) & & & & & \\
Vehicle & 6 & $0.68 \pm 0.08$ & $0.76 \pm 0.10$ & $0.69 \pm 0.18$ & $0.70 \pm 0.15$ \\
ET & 8 & $0.64 \pm 0.05$ & $0.72 \pm 0.08$ & $0.64 \pm 0.08$ & $0.80 \pm 0.11$ \\
ET + captopril & 6 & $0.59 \pm 0.05$ & $0.55 \pm 0.11$ & $0.69 \pm 0.12$ & $0.75 \pm 0.12$ \\
ET + enalapril & 6 & $0.69 \pm 0.11$ & $0.50 \pm 0.07$ & $0.54 \pm 0.04$ & $0.71 \pm 0.14$ \\
ET + benidipine & 6 & $0.68 \pm 0.07$ & $0.60 \pm 0.13$ & $0.56 \pm 0.10$ & $0.57 \pm 0.16$ \\
ET + nilvadipine & 6 & $0.62 \pm 0.06$ & $0.55 \pm 0.10$ & $0.66 \pm 0.12$ & $0.74 \pm 0.04$ \\
\hline
\end{tabular}

Results are expressed as means \pm s.E. ACE, angiotensin converting enzyme; UV, urine volume ; UNaV, urinary sodium excretion ; ET, endothelin. Analysis of variance for repeated measurements revealed a significant change in urine volume in rats given endothelin at a rate of $60 \mu \mathrm{g} / \mathrm{kg} /$ day in combination with captopril (50 $\mathrm{mg} / \mathrm{kg} /$ day) $(p<0.05)$ or with enalapril $(6 \mathrm{mg} / \mathrm{kg} /$ day $)(p<0.05)$ compared to that in rats given endothelin alone. ${ }^{* *} p<0.01$ vs. values in rats given endothelin alone.

accompanied by natriuresis, suggesting that the reduction of blood pressure is not secondary to the renal effects of these agents. In addition, the similar antihypertensive effect of angiotensin converting enzyme inhibitors to calcium channel blockers in endothelin-infused rats may also suggest the presence of the common pathway in the hypotensive mechanism of these two lines of drugs.

The possibility that deterioration of the molecular constitution of captopril or enalapril, while it is being chronically administered, resulting in a substance with vasodilatory actions, could be ruled out, since vasopressor responses to angiotensin I were inhibited by $90 \%$ and that to angiotensin II was not attenuated in rats administered with captopril or enalapril at a same dose employed in the present study for up to 6 days.

The most likely mechanism in the hypotensive effect of angiotensin converting enzyme inhibitors is the blockade of conversion of angiotensin I to angiotensin II, thereby lowering plasma levels of angiotensin II. Consistent with this interpretation are the recent reports by several investigators (MacGregor et al. 1981 ; Morton et al. 1982). There is a clear need for data concerning the longer term effects of captopril or enalapril without lowered angiotensin II levels to clarify the mechanism of antihypertensive effect of both drugs in these models of rats, since 


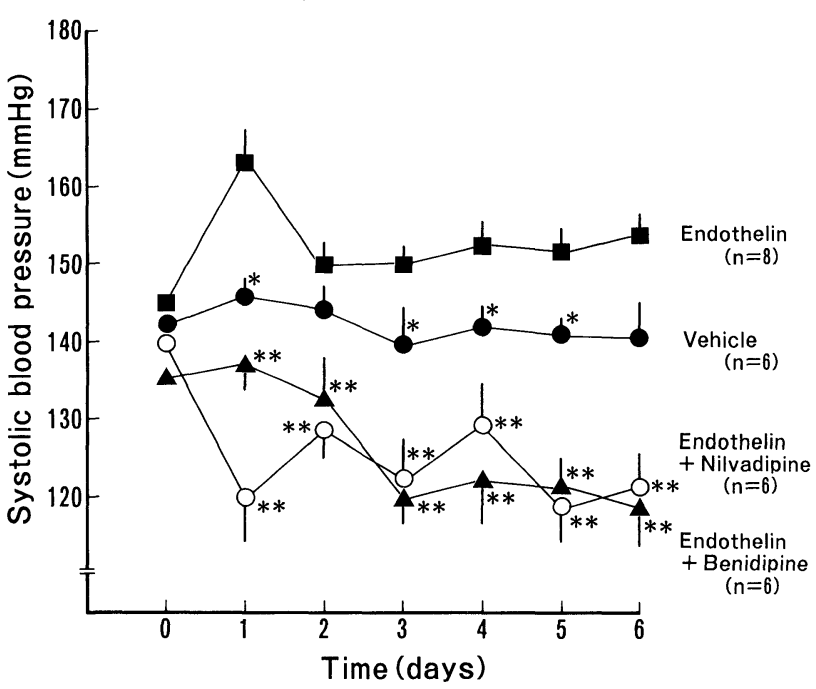

Fig. 3. Effect of benidipine or nilvadipine on the elevation of blood pressure induced by chronic infusion of endothelin in conscious rats. Daily systolic blood pressure in rats infused with endothelin alone at a rate of $60 \mu \mathrm{g} / \mathrm{kg} /$ day (ロ), with endothelin combined with $6 \mathrm{mg} / \mathrm{kg}$ /day of benidipine $(\boldsymbol{\Lambda})$, with endothelin combined with $10 \mathrm{mg} / \mathrm{kg} /$ day of nilvadipine (O), and with vehicle alone $(\bullet)$. Results are means \pm s.e.. Analysis of variance for repeated measurements revealed a significant change in systolic blood pressure in rats given endothelin and benidipine $(p<0.01)$, endothelin and nilvadipine $(p<0.01)$, or vehicle alone $(p<0.05)$ compared to that in rats given endothelin alone. ${ }^{*} p<0.05 ;{ }^{* *} p<0.01$ vs. values in rats given endothelin alone.

some investigators described that an angiotensin II infusion clearly reversed the observed blood pressure reduction by inhibitors of angiotensin converting enzyme. In the present study, effects of captopril or enalapril were reversed by providing continuously exogenous angiotensin II at a subpressor dose. As described previously, chronic angiotensin II infusion at doses of more than $100 \mathrm{ng} / \mathrm{min}$ induced significant elevations of blood pressure in rats (Yasujima et al. 1986a). The hypertensive effects of angiotensin II at doses to induce pressor effects was not modulated by the administration of captopril or enalapril (Yasujima et al. 1990b). Yanagisawa et al. (1988) reported that the vasoconstrictive effect of endothelin is dependent on extracellular calcium ion. Hirata et al. (1988) also reported that the sustained increase in cytosolic free calcium ion concentrations stimulated by endothelin is entirely dependent on calcium ion influx through the voltagedependent calcium ion channels. As confirmed in the present study, the antihypertensive effect of calcium channel blockers in endothelin-infused rat might be explained by their own action on calcium channels. To our knowledge, the antihypertensive effect of angiotensin converting enzyme inhibitors in endothelininfused rats has not been previously reported, whereas it has been well document- 
ed that in vitro and in vivo calcium channel blockers attenuated acute vasopressor effects of exogenous endothelin (Hirata et al. 1988; Yanagisawa et al. 1988; Yasujima et al. 1990a). At the moment, the exact mechanism is still unknown.

In summary, the present results indicate that the reduced sensitivity of peripheral arteries to endothelin may be involved in the mechanism of the hypotensive action of angiotensin converting enzyme inhibitors, dependent on the suppressed angiotensin II formation. Furtheremore, the similar effect of the angiotensin converting enzyme inhibitors to calcium channel blockers in endothelin-infused rats suggest the existence of common pathway in the hypotensive mechanism of these two lines of drugs.

\section{Acknowledgments}

We wish to acknowledge the excellent technical assistance of Keiko Shiraishi, Michiko Okamoto and Naeko Hatanaka, and the secretarial assistance of Junko Okazaki. We are also grateful to Sankyo Co., Tokyo, Japan, Banyu Pharmaceut. Co., Tokyo, Japan, Kyowa Hakko Kogyo Co., Tokyo, Japan and Fujisawa Pharmaceut., Co., Tokyo, Japan for supplying captopril, enalapril, benidipine and nilvadipine, respectively. This study was supported by the Grant-in-Aid for Scientific Research (61132005 and 62570376) from the Ministry of Education, Science and Culture of Japan.

\section{References}

1) Fujii, Y., Suzuki, H., Katsumura, H., Nakajima, S. \& Saruta, T. (1988) Hormonal and renal responses to oral once-daily calcium entry blockers in normotensive and hypertensive persons. J. Cardiovasc. Pharmacol., 11, 438-443.

2) Hirata, Y. (1990) Endothelin receptor and its action. In : Endothelin, edited by T. Masaki, Y. Hirata \& M. Yanagisawa, Chugai Igakusha, Tokyo, pp. 6-10. (Japanese)

3) Hirata, Y., Yoshimi, H., Tanaka, S., Watanabe, T.X., Kumagai, S., Nakajima, K. \& Sakakibara, S. (1988) Cellular mechanism of action by a novel vasoconstrictor endothelin in cultured rat vascular smooth muscle cells. Biochem. Biophys. Res. Commun., 154, 868-875.

4) Johnston, C.I., Yasujima, M. \& Clappison, B.H. (1981) The kallikrein-kinin system and angiotensin converting enzyme inhibition in hypertension. In: Angiotensin Converting Enzyme Inhibitors, edited by Z.P. Horovitz, Urban and Schwarzenberg, Baltimore-Munich, pp. 123-139.

5) Kubo, K., Karasawa, A., Shuto, K. \& Nakamizo, N. (1985) Antihypertensive effects of a novel dihydropyridine-type Ca antagonist, KW-3049. Jpn. J. Pharmacol., 39, Suppl., 217.

6) MacGregor, G.A., Markandu, N.D., Roulston, J.E., Jones, J.C. \& Morton, J.J. (1981) Maintenance of blood pressure by the renin angiotensin system in normal man. Nature, 291, 329-331.

7) Morton, J.J., Tree, M. \& Casals Stenzel, J. (1982) Effect of infused captopril on blood pressure and the renin-angiotensin aldosterone system in normal dogs subjected to varying sodium balance. Am. J. Cardiol., 48, 1395-1400.

8) Ohtsuka, M., Ono, T., Hiroi, J., Esumi, K., Kikuchi, H. \& Kumada., S. (1983) Comparison of the cardiovascular effects of FR 34235, a new dihydropyridine, with other calcium antagonists. J. Cardiovasc. Pharmacol., 5, 1074-1082.

9) Pfeffer, J.M., Pfeffer, M.A. \& Frohlich, E.D. (1971) Validity of an indirect tail-cuff method for determining systolic blood pressure in unanesthetized normotensive and spontaneously hypertensive rats. J. Lab. Clin. Med., 78, 957-962. 
10) Yanagisawa, M., Kurihara, H., Kimura, S., Tomobe, Y., Kobayashi, M., Matsui, Y., Yazaki, Y., Goto, K. \& Masaki, T. (1988) A novel potent vasoconstrictor peptide produced by vascular endothelial cells. Nature, 332, 411-415.

11) Yasujima, M., Abe, K., Kohzuki, M., Tanno, M., Kasai, Y., Sato, M., Omata, K., Kudo, K., Takeuchi, K., Hiwatari, M., Kimura, T., Yoshinaga, K. \& Inagami, T. (1986a) Effect of atrial natriuretic factor on angiotensin II-induced hypertension in rats. Hypertension, 8, 748-753.

12) Yasujima, M., Abe, K., Tanno, M., Kohzuki, M., Omata, K., Kasai, Y., Kudo, K., Tsunoda, K., Sato, M., Chiba, S. \& Yoshinaga, K. (1986b) Effects of sodium and angiotensin II on urinary active and inactive kallikrein in rats. J. Hypertens., 4, 1318.

13) Yasujima, M., Abe, K., Kanazawa, M., Yoshida, K., Sato, M., Takeuchi, K., Kudo, K., Kohzuki, M., Omata, K., Yabe, T., Hiwatari, M., Sato, T. \& Yoshinaga, K. (1990a) Calcium channel blockers reverse the sustained elevation of blood pressure induced by chronic infusion of endothelin in conscious rats. Tohoku J. Exp. Med., 160, 157-165.

14) Yasujima, M., Abe, K., Tanno, M., Kanazawa, M., Yoshida, K., Sato, M., Takeuchi, K. \& Yoshinaga, K. (1990b) The depressor mechanism of enalapril in rats made hypertensive by norepinephrine or vasopressin. Nephron, 55, Suppl. 1, 81-84. 